\title{
KAJIAN SISTEM PERLADANGAN DI KABUPATEN BOLAANG MOGONDOW (STUDI KASUS PERLADANGAN DI KPHP WILAYAH II KABUPATEN BOLAANG MONGONDOW)
}

\author{
Susilaningsih Lasabuda \\ Hengki Djemie Walangitan \\ Nordy Waney
}

\begin{abstract}
The study aimed to (1) describe the characteristics of the socio-economic, (2) describe the characteristic of ecological farming in the region KPHP unit II Bolaang Mongondow district, and (3) analyze the development strategy KPHP Unit II in the district based on empowerment Bolaang Mongondow cultivators. This research was conducted with descriptive and semi-quantitative approach. Data analysing for the development of management strategies used SWOT analysis. The primary data obtained through interviews in three (3) villages namely Pindolili, Village Pindol and Village Totabuan to 20 informants, consisting of 3 (three) the village chief, two religious leaders in the two (2) village, 2 (two) historians the formation of the village and 12 (twelve) cultivators in three (3) villages. While the secondary data obtained through statistical data and information obtained from the forestry policy forestry official website. Results of research on (1) socio-economic condition around the area KPHP unit II Bolaang Mongondow district shows that the agricultural sector is still the main source of livelihood of society. Socio-cultural conditions of communities in the study area are a heterogeneous society with different ethnic groups. They are still implement a culture or tradition that can threaten the sustainability of their livelihoods; (2) Ecological condition in the area KPHP unit II shows that the high danger of erosion due to geography land that shaped mountains with slope ranging from moderate to steep and the actions of farming and poor land management on critical land of steep hills. (3) Based on the results of the SWOT analysis for development strategy is the designation of priority and urgency, the development of nature tourism potential for increased use of environmental services, increased perception and participation of the formal integration of development and the development of food security by reforestation and forest conservation. The implementation strategy of forest management in the region KPHP unit II Bolaang Mongondow needs to be done in the form of maintenance of the water catchment area to ensure the availability of water production for the dam in the village Pindol, increasing role in the development of tourism and recreation participation of the parties primarily concerned to control encroachment and set the direction and strategy of development associated with the function of the ministry of forestry.
\end{abstract}

Keywords: farming systems, SWOT analysis, KPHP region II, District of Bolaang Mongondow, North Sulawesi

\section{ABSTRAK}

Penelitian bertujuan untuk (1) mendeskripsikan karakteristik sosial ekonomi dan (2) ekologi perladangan di wilayah KPHP unit II Kabupaten Bolaang Mongondow, dan (3) menganalisis strategi pembangunan KPHP Unit II di kabupaten Bolaang Mongondow berbasis pada pemberdayaan peladang. Penelitian ini dilakukan dengan pendekatan deskriptif dan semi kuantitatif. Pengembangan strategi pengelolaan menggunakan analisis SWOT. Data primer diperoleh melalui wawancara di 3 (tiga) desa yaitu Desa Pindolili, Desa Pindol dan Desa Totabuan terhadap 20 informan, yang terdiri dari 3 (tiga) Kepala Desa, 2 tokoh agama di 2 (dua) desa, 2 (dua) ahli sejarah terbentuknya desa dan 12 (dua belas) peladang di 3 (tiga) desa. Sedangkan data sekunder diperoleh melalui data statistik, informasi kebijakan kehutanan diperoleh dari website resmi kehutanan. Hasil penelitian menunjukkan bahwa (1) kondisi ekonomi masyarakat sekitar wilayah KPHP unit II Kabupaten Bolaang Mongondow bertumpu pada sektor pertanian yang masih merupakan sumber mata pencaharian utama masyarakat. Kondisi sosial-budaya dari masyarakat di wilayah penelitian merupakan masyarakat heterogen dengan berbagai etnis yang masih menerapkan budaya atau tradisi yang dapat mengancam keberlanjutan mata pencaharian mereka di bidang pertanian; (2) Keadaan ekologi di wilayah KPHP unit II menunjukkan bahwa tingginya bahaya erosi yang terjadi disebabkan kondisi geografi lahan yang berbentuk pegunungan dengan kemiringan lereng yang berkisar antara sedang sampai curam serta tindakan usaha tani dan pengelolaan lahan yang buruk pada lahan-lahan kritis diperbukitan terjal;. (3) Berdasarkan hasil análisis SWOT maka strategi pengembangan adalah strategi penetapan lokasi prioritas dan urgen, pengembangan potensi pariwisata alam untuk peningkatan pemanfaatan jasa lingkungan, peningkatan persepsi dan partisipasi para pihak formal serta pengembangan keterpaduan pembangunan ketahanan pangan dengan kegiatan reboisasi dan konservasi kawasan hutan. Strategi pelaksanaan pengelolaan hutan di wilayah KPHP unit II Kabupaten Bolaang Mongondow yang perlu dilakukan berupa pemeliharaan daerah tangkapan air untuk menjamin ketersediaan produksi air bagi waduk yang ada di Desa Pindol, meningkatkan peran dalam pengembangan pariwisata dan rekreasi adanya partisipasi para pihak terutama berkaitan dengan pengendalian perambahan hutan dan menetapkan arah dan strategi pembangunan yang terkait dengan fungsi kementerian kehutanan.

Kata kunci: sistem perladangan, analisa SWOT, Wilayah KPHP Unit II, Kabupaten Bolaang Mongondow 


\section{PENDAHULUAN}

Berdasarkan SK Menteri Kehutanan Nomor : 796 / Menhut-II/2009 tanggal 7 desember 2009 tentang penetapan wilayah KPHP unit II dan KPHP unit IV. Wilayah KPHP unit II terletak dalam wilayah Kabupaten Bolaang Mongondow Sulawesi utara yang berada pada ketinggian sekitar 600 sampai puncak gunung sekitar 900 meter dari permukaan laut (Mdpl) dengan luas $20.699 \mathrm{Ha}$. Secara geografis KPHP unit II Bolaang Mongondow terletak pada $1^{0} 06^{\prime}-1^{0} 20^{\prime}$ Lintang Utara dan $124^{0} 45^{\prime}-124^{0} 58^{\prime}$ Lintang Selatan. Berdasarkan wilayah administrasi pemerintahan wilayah KPHP unit II kabupaten Bolaang Mongondow terbagi atas 3 (tiga) wilayah kecamatan yaitu kecamatan Dumoga timur, Bolaang, dan kecamatan Lolak yang meliputi 15 desa sekitar hutan.

Perladangan dalam kawasan hutan merupakan suatu fenomena sosial ekonomi dan budaya Perladangan dalam kawasan hutan di Sulawesi Utara telah menjadi masalah utama dalam kaitan dengan degradasi hutan. Aspek ekologi dampak yang ditimbulkan seperti banjir, longsor, hilangnya keanekaragaman hayati serta kerugian perekonomian hayati. Aspek ekonomi kerugian yang ditimbulkan diantaranya hilangnya potensi pendapatan negara dari industri hasil hutan kayu dan non kayu, serta dampak turunannya (multiplier effect). Kondisi hutan alam produksi terus menyusut luas dan produktivitasnya dimana hampir semua kawasan hutan produksi bekas tebangan telah diokupasi masyarakat menjadi areal perladangan.

Pada dasarnya sistem KPH menerapkan asas desentralisasi dan memberikan hak kepemilikan (property right) hingga pada tingkat tapak sehingga kerusakan yang diakibatkan oleh sifat sumberdaya yang tidak dapat dipilah (non exludable) dapat diatasi. Hak kepemilikan (property right) adalah suatu bentuk penguasaan dan pengusahaan secara hukum yang diharapkan dapat terbangun sistem pemanfaatan yang berkelanjutan karena pihak pengelola merasa memiliki dengan tugas dan bertanggung jawab yang jelas dan terukur, dengan adanya hak tersebut maka kewenangan untuk mengatur dan membatasi dapat diterapkan sehingga tujuan pengelolaan hutan berkelanjutan dapat diwujudkan (Walangitan, dkk. 2014).
Kendala yang dihadapi dalam implementasi pengelolaan KPHP unit II tersebut adalah adanya aktifitas perladangan dalam kawasan. Langi dan Walangitan (2013) melaporkan bahwa sekitar 25 persen dari luas kawasan hutan tersebut telah menjadi perladangan, sehingga diperlukan upaya yang tepat agar masyarakat peladang dapat menjadi mitra pengelolaan hutan. Berdasarkan laporan Walangitan (2014) maka perladangan di KPHP unit II adalah 570,423\%.

\section{Rumusan Masalah}

Permasalahan penelitian dirumuskan menjadi beberapa pertanyaan penelitian sebagai berikut:

1. Bagaimana karakteristik ekologi perladangan di wilayah KPHP unit II kabupaten Bolaang Mongondow.

2. Bagaimana karakteristik sosial ekonomi dan budaya peladang di wilayah KPHP unit II di kabupaten Bolaang Mongondow.

3. Bagaimana strategi pengelolaan kawasan untuk menjamin terwujudnya pengelolaan kawasan hutan dengan mempertimbangkan aspek ekonomi sosial dan budaya masyarakat.

\section{Tujuan Penelitian}

1. Mendeskripsikan karakteristik ekologi perladangan di Wilayah KPHP unit II kabupaten Bolaang Mongondow.

2. Mendeskripsikan karakteristik ekonomi, dan sosial budaya peladang di Wilayah KPHP unit II kabupaten Bolaang Mongondow.

3. Mengkaji strategi pengelolaan KPHP unit II di Kabupaten Bolaang Mongondow

\section{METODOLOGI PENELITIAN}

\section{Lokasi dan Waktu Penelitian}

Penelitian ini dilaksanakan di wilayah KPHP unit II kabupaten Bolaang Mongondow dengan desa sampel yaitu Desa Pindolili, Desa Pindol dan Desa Totabuan kecamatan Lolak. Pengumpulan data dilaksanakan sejak bulan Januari 2016 sampai dengan April 2016.

\section{Desain Penelitian}

Penelitian ini menggunakan desain kualitatif dan desain semi kuantitatif Analisis kualitatif menggunakan bentuk kata atau skala 
deskriptif untuk menjelaskan seberapa besar potensi resiko yang akan diukur. Hasilnya, misalnya resiko dapat termasuk dalam resiko rendah, resiko sedang, resiko tinggi. Analisis kualitatif digunakan untuk kegiatan skrining awal pada resiko yang membutuhkan analisis lebih rinci dan lebih mendalam. Analisis Semikuantitatif, menggunakan nilai numerik.kualitas dari analisis tergantung pada akurasi dan kelengkapan data yang ada.

\section{Sumber Data}

Sumber data dalam penelitian ini adalah data primer dan data sekunder. Data primer adalah data yang langsung diperoleh peneliti dengan melakukan wawancara kepada informan dan data sekunder adalah data pendukung yang diperlukan seperti laporan kerja aturan dan data lainnya yang berhubungan dengan objek penelitian.

\section{Teknik Pengumpulan Data}

Pengumpulan data dilakukan sebagaimana dalam Sugiono (2008), yaitu : (1) Observasi, dilakukan dengan cara pengamatan objek penelitian, (2) Wawancara, yang bersifat mendalam dimaksudkan untuk mendapatkan informasi penting yang belum terungkap sebelumnya, (3) Studi dokumen, dokumen yang digunakan adalah merupakan data pendukung terhadap hasil pengamatan dan wawancara.

\section{Metode Analisis SWOT}

A. Pembobotan Nilai Urgensi $(\mathrm{NU})=$ Nilai urgensi digunakan untuk menentukan tingkat urgensinya pada masing-masing faktor terhadap pencapaian tujuan dan faktor diberi bobot antara 1 sampai dengan 5, tergantung tingkat urgensinya yaitu :

1) Nilai urgensi 5 , menyatakan sangat tinggi nilai urgensinya

2) Nilai urgensi 4, menyatakan tinggi nilai urgensinya

3) Nilai urgensi 3, menyatakan cukup tinggi nilai urgensinya

4) Nilai urgensi 2, menyatakan kurang tinggi nilai urgensinya

5) Nilai urgensi 1 , menyatakan sangat kurang tinggi nilai urgensinya

B. Pembobotan Nilai Dukungan (ND)

Nilai dukungan disini digunakan untuk menunjukkan besarnya dukungan setiap faktor baik bersifat mendorong maupun menghambat terhadap pencapaian tujuan dan diberi bobot 1 sampai 5 tergantung tingkat dukungannya, yaitu :

1) Nilai dukungan 5 , menyatakan sangat kuat dukungannya, sangat kuat hambatannya

2) Nilai dukungan 4,menyatakan kuat dukungannya,kuat hamabatannya

3) Nilai dukungan 3, menyatakan cukup kuat dukungannya cukup kuat hambatannya

4) Nilai dukungan 2 , menyatakan kurang kuat dukungannya kurang kuat hambatannya

5) Nilai dukungan 1, menyatakan sangat kuran kuat dukungannya sangat kurang kuat hambatannya

C. Nilai keterkaitan (NK)

Nilai keterkaitan akan menunjukkan besarnya keterkaitan satu faktor pada faktorfaktor lainnya terhadap pencapaian tujuan dan diberi bobot 0 sampai 5 tergantung dari kuatnya keterkaitan masing-masing faktor dengan faktor lainnya yaitu :

1) Nilai keterkaitan 5 , menunjukkan adanya keterkaitan yang sangat kuat antar faktor

2) Nilai keterkaitan 4, menunjukkan adanya keterkaitan yang kuat antar faktor

3) Nilai keterkaitan 3, menunjukkan adanya keterkaitan yang cukup kuat antar faktor

4) Nilai keterkaitan 2, menunjukkan adanya keterkaitan yang kurang kuat antar faktor

5) Nilai keterkaitan 1, menunjukkan adanya keterkaitan yang sangat kuat antar faktor

6) Nilai keterkaitan 0, menunjukkan tidak adanya keterkaitan antar faktor.

Evaluasi faktor internal utama dan faktor eksternal utama digunakan rumus dalam penghitungan bobot :

1) Bobot Faktor $(\mathrm{BF})=\mathrm{UN}: \Sigma \mathrm{UN} \times 100 \%$

2) Nilai Bobot dukungan $(\mathrm{NBD})=\mathrm{BF} \times \mathrm{ND}$ : $100 \%$

3) Nilai Rata-Rata Keterkaitan $(\mathrm{NRK})=\mathrm{NK}$ : Jumlah faktor

4) Nilai Bobot Keterkaitan $(\mathrm{NBK})=\mathrm{NRK} x$ BF : $100 \%$

5) Total Nilai Bobot $(\mathrm{TNB})=\mathrm{NBD}+\mathrm{NBK}$

Selanjutnya hasil dari masing-masing $\mathrm{UN}, \mathrm{BF}, \mathrm{ND}, \mathrm{NBD}, \mathrm{NK}, \Sigma \mathrm{NK}, \mathrm{NRK}, \mathrm{NBK}, \mathrm{TNB}, \mathrm{Ra}$ ngking dimasukkan dalam tabel faktor internal dan eksternal sehingga berdasarkan rangking yang diperoleh dapat disimpulkan hasil dari análisis SWOT dalam bentuk kuadran. 


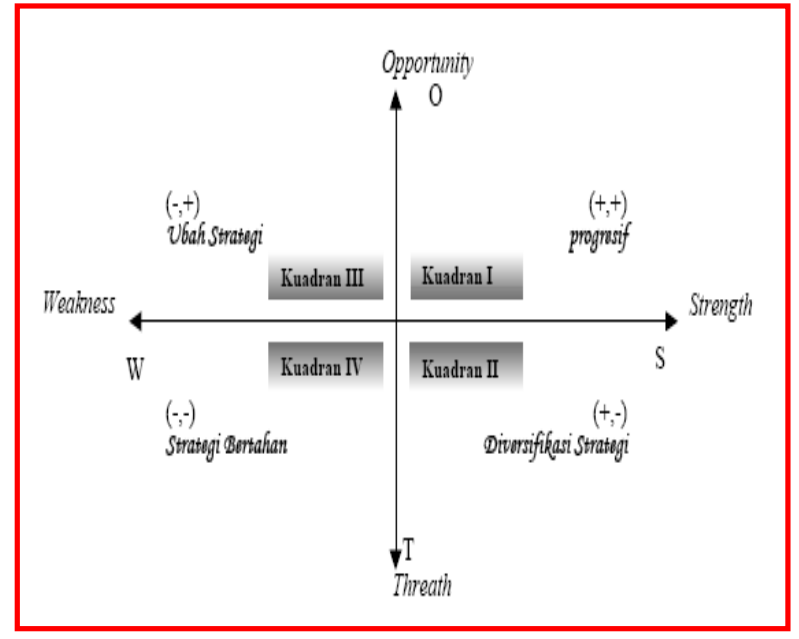

Gambar 1. Bentuk Kuadran Hasil Analisis SWOT

\section{HASIL DAN PEMBAHASAN}

Secara geografis KPHP unit II Bolaang Mongondow terletak pada $1^{0} 06^{\prime}-1^{0} 20^{\prime}$ Lintang Utara dan $124^{\circ} 45^{\prime}-124^{0} 58^{\prime}$ Lintang Selatan. Berdasarkan wilayah administrasi pemerintahan wilayah KPHP unit II kabupaten Bolaang Mongondow terbagi atas 3 (tiga) wilayah kecamatan yaitu kecamatan Dumoga timur, Bolaang, dan kecamatan Lolak yang meliputi 15 desa sekitar hutan.

Hasil analisis spasial tata guna hutan, wilayah KPHP unit II terdiri atas tiga fungsi kawasan hutan yaitu kawasan hutan lindung (HL), Hutan produksi terbatas (HPT) dan hutan produksi tetap (HP) dengan luas masing-masing disajikan pada Tabel 1.

Tabel 1. Luas kawasan wilayah KPHP unit II Bolaang Mongondow menurut tataguna hutan.

\begin{tabular}{lc}
\hline Nama kawasan hutan & Luas (ha) \\
\hline HL. S. Toadan I & $1.612,24$ \\
HL. S. Toadan II & 921,99 \\
HL. Labuan uki & 527,37 \\
Sub total HL & $\mathbf{3 . 0 6 1 , 6 0}$ \\
\hline HP S. Onggak Mongondow & $6.714,42$ \\
HPT. Labuan uki & $4.922,45$ \\
HPT. S. Onggak Dumoga & $6.001,45$ \\
Sub total HPT & $10.923,90$ \\
\hline Grand total & $\mathbf{2 0 . 6 9 9 , 9 2}$ \\
\hline Sumber: dihitung pada & peta KPHP unit \\
\multicolumn{1}{c}{$\quad \mathbf{2 0 1 3}$} &
\end{tabular}

\section{Kondisi Tutupan Lahan}

Data penggunaan lahan diperoleh dari interpretasi citra satelit (2011) menunjukkan bahwa terdapat 8 (delapan) jenis tutupan lahan pada kawasan hutan lindung tutupan lahan didominasi oleh hutan sekunder dan semak belukar dan sisanya berupa perladangan. Kondisi ini relative sama pada kawasan hutan produksi tetap (HP) Sedangkan pada areal (HPT) sekitar $75 \%$ dari luas areal berupa hutan sekunder dan sekitar $20 \%$ adalah perladangan. Dapat dilihat pada Tabel 2.

Kawasan hutan produksi (HP dan HPT) yang telah dirambah menjadi areal perladangan sekitar 5400 Ha yang tersebar pada lereng datar hingga lereng curam. Hasil pengamatan sepintas waktu melewati wilayah Desa Pindol hingga Desa Totabuan terlihat bahwa potensi kayu pada kawasan hutan sekunder ditumbuhi oleh berbagai jenis pohon tumbuh cepat seperti Antocepalus cadamba.

\section{Kondisi Topografi}

Keadaan topografi kawasan hutan KPHP unit II sebagian besar mempunyai relief bergelombang sampai berbukit. Kondisi lereng didominer lereng curam dan sangat curam sekitar $85 \%$, sisanya berlereng landai hingga agak curam. Secara rinci luas kawasan menurut lereng disajikan pada Tabel 3.

Hasil pengamatan berdasarkan kondisi biofisik di wilayah KPHP unit II kabupaten Bolaang Mongondow adalah tingginya bahaya erosi yang terjadi disebabkan kondisi geografi lahan yang berbentuk pegunungan dengan kemiringan lereng yang berkisar antara sedang sampai curam serta tindakan usaha tani dan pengelolaan lahan yang buruk pada lahan-lahan kritis diperbukitan terjal di daerah penelitian.

Berdasarkan kondisi tersebut hasil pengamatan mengenai kondisi wilayah KPHP unit II kabupaten Bolaang Mongondow menunjukkan karakteristik sosial ekonomi di wilayah KPHP unit II kabupaten Bolaang Mongondow bahwa sektor pertanian masih merupakan sumber mata pencaharian utama masyarakat. Sektor pertanian terdiri dari sub sektor tanaman pangan, perkebunan, perikanan dan peternakan. Komoditas yang menonjol dari hasil-hasil tanaman pangan terdiri atas padi/beras dan jagung, hasil perkebunan masih mengandalkan kelapa/kopra dan mulai mengembangkan komoditas coklat serta hasil-hasil perikanan laut terutama perikanan tangkap. 
Tingkat pendapatan rumah tangga terhadap 20 responden disekitar wilayah KPHP unit II, pendapatan rumah tangga responden bervariasi mulai dari Rp. 1.000.000,- per bulan sampai lebih dari Rp.3.000.000.- per bulan, sedangkan sebagian besar berada diantara Rp. 1.000.000.Rp.2.000.000.- per bulan. Gambaran secara umum pendapatan masyarakat, nilainya relatif cukup untuk memenuhi pengeluaran rumah tangga sehari-hari. Selain mengusahakan tanaman pertanian dan perkebunan masyarakat juga menjadi buruh artinya sambil menunggu masa panen tanaman masyarakat mencari alternatif pekerjaan untuk memenuhi kebutuhan hidup rumah tangga. Sebagian kelompok masyarakat pendapatannya relatif memadai untuk memenuhi berbagai kebutuhan konsumsi sesuai dengan kondisi diwilayah tersebut. Sebagian kebutuhan konsumsi masih dapat dipenuhi melalui transaksi lainnya yang tidak dalam bentuk uang seperti untuk kebutuhan sayur-mayur dan bumbu-bumbu yang diambil dari hasil kebun sendiri serta lauk pauk termasuk konsumsi ikan dapat ditangkap dari hasil laut disekitar wilayah desa mereka.

Dari hasil gambaran diatas maka pengelolaan wilayah KPHP unit II Kabupaten Bolaang Mongondow ada pada kuadran III (difersifikasi strategi) dapat dilihat pada gambar 2.
Artinya posisi ini menandakan masih lemahnya organisasi KPHP unit II kabupaten Bolaang Mongondow namun sangat berpeluang, rekomendasi strategi yang direkomendasikan adalah ubah strategi sebelumnya karena dikhawatirkan sulit untuk menangkap peluang yang ada sekaligus memperbaiki kinerja organisasi tersebut.

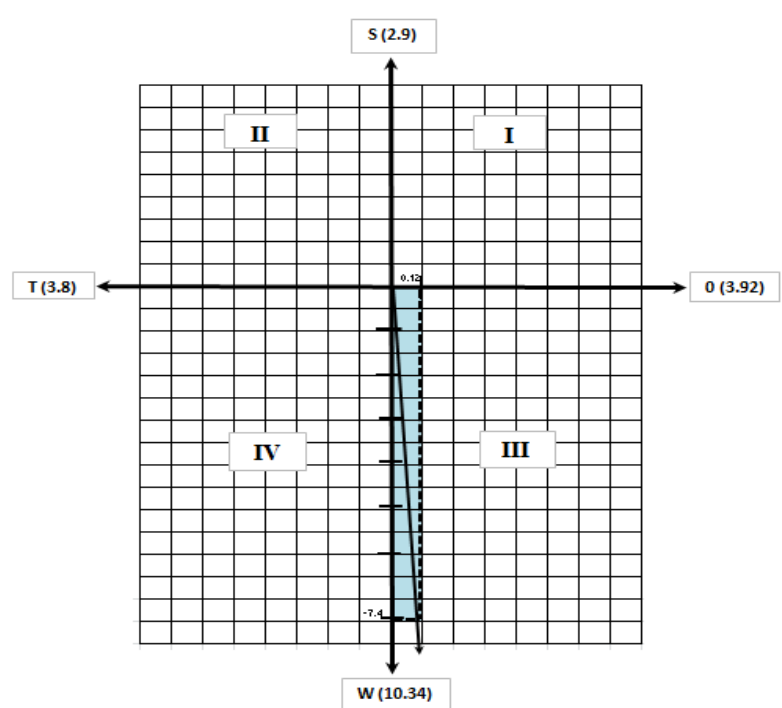

Gambar 2. Kuadran hasil perhitungan dengan hasil analisis SWOT

Tabel 2. Kondisi Tutupan Lahan Wilayah KPHP Unit II kabupaten Bolaang Mongondow

\begin{tabular}{|c|c|c|c|}
\hline Kawasan Hutan & Penutupan lahan & Total & Persentase \\
\hline \multirow[t]{4}{*}{ HL } & Hutan lahan kering sekunder & 2127.47 & 69.48 \\
\hline & Pertanian lahan kering & 61.09 & 1.99 \\
\hline & Pertanian lahan kering campur semak & 304.46 & 9.94 \\
\hline & Semak belukar & 568.58 & 18.57 \\
\hline HL Total & & 3061.60 & \\
\hline \multirow[t]{4}{*}{ HP } & Hutan lahan kering sekunder & 3448.28 & 51.35 \\
\hline & Pertanian lahan kering & 0.16 & 0.0023 \\
\hline & Pertanian lahan kering campur semak & 3181.92 & 47.38 \\
\hline & Semak belukar & 84.06 & 1.25 \\
\hline HP Total & & 6714.42 & \\
\hline \multirow[t]{4}{*}{ HPT } & Hutan lahan kering sekunder & 7994.74 & 73.18 \\
\hline & Pertanian lahan kering & 249.94 & 2.28 \\
\hline & Pertanian lahan kering campur semak & 1906.66 & 17.40 \\
\hline & Semak belukar & 772.56 & 7.072 \\
\hline HPT Total & & 10923.90 & \\
\hline Grand Total & & 20699.92 & \\
\hline
\end{tabular}


Tabel 3. Luas kawasan wilayah KPHP unit II Kabupaten Bolaang Mongondow menurut kelas lereng dan fungsi kawasan.

\begin{tabular}{llll}
\hline Kawasan Hutan & Kelas Kelerengan & Luas (Ha) & Persentase \\
\hline HL & Datar & 154.38 & 5.04 \\
& Landai & 122.00 & 3.95 \\
& Agak Curam & 49.19 & 1.61 \\
& Curam & 1399.67 & 45.72 \\
& Sangat Curam & 1336.35 & 43.65 \\
\hline HL Total & & $\mathbf{3 0 6 1 . 6 0}$ & 4.94 \\
\hline HP & Datar & 331.43 & 0.06 \\
& Landai & 3.77 & 2.89 \\
& Agak Curam & 194.15 & 53.76 \\
& Curam & 3609.60 & 38.36 \\
\hline HP Total & Sangat Curam & 2575.47 & 1.90 \\
\hline HPT & & $\mathbf{6 7 1 4 . 4 2}$ & 1.74 \\
& Datar & 207.82 & 4.03 \\
& Landai & 190.40 & 28.24 \\
& Agak Curam & 440.87 & 64.21 \\
\hline HPT Total & Curam & 3084.87 & \\
\hline Grand Total & Sangat Curam & 6999.92 & $\mathbf{1 0 9 2 3 . 9 0}$ \\
\hline
\end{tabular}

Sumber: Walangitan, H,dan Langi 2013 dianalisis pada peta skala 1 : 50.000.

Tabel 4. Penentuan Strategi Pelaksanaan Pengelolaan Kawasan Hutan Wilayah KPHP unit II Kabupaten Bolaang Mongondow dengan Matriks SWOT.

\begin{tabular}{|c|c|c|}
\hline EKSTERNAL & $\begin{array}{l}\text { Kekuatan (S) } \\
\text { 1. Adanya komitmen yang } \\
\text { kuat dari KPH dalam } \\
\text { menjalankan tugas }\end{array}$ & $\begin{array}{l}\text { kelemahan (W) } \\
\text { 1. Keterlibatan stakeholder belum melembaga dalam } \\
\text { mendukung kegiatan perlindungan dan pengamanan } \\
\text { 2. Keterbatasan Sumber daya manusia (SDM) } \\
\text { 3. Anggaran KPH terbatas pada kegiatan pengamanan } \\
\text { kawasan dan pemberian bantuan kepada petani } \\
\text { 4. Adanya peraturan perundangan yang menjadi acuan } \\
\text { dalam penegakan hukum }\end{array}$ \\
\hline $\begin{array}{l}\text { Peluang (O) } \\
\text { 1. Adanya dukungan sebagian besar } \\
\text { masyarakat untuk memulihkan } \\
\text { kondisi kawasan agar kawasan } \\
\text { kembali seperti dulu juga } \\
\text { dukungan masyarakat pengguna } \\
\text { air irigasi disekitar agar kegiatan } \\
\text { pengelolaan kawasan dilakukan } \\
\text { secepatnya }\end{array}$ & $\begin{array}{l}\text { S101: menjaga komitmen dan } \\
\text { meningkatkan kapasitas SDM } \\
\text { dalam menggalang partisipasi } \\
\text { masyarakat dalam } \\
\text { pengelolaan dan } \\
\text { mengamankan wilayah KPH }\end{array}$ & $\begin{array}{l}\text { W101: mengembangkan model pengelolaan kolaborasi } \\
\text { W201: memberdayakan peran LSM, dan tokoh } \\
\text { masyarakat sekitar kawasan }\end{array}$ \\
\hline $\begin{array}{l}\text { 2. Adanya kesadaran yang tinggi dari } \\
\text { pemerintah daerah bahwa KPH } \\
\text { sangat strategi mendukung } \\
\text { ketahanan pangan di Sulawesi } \\
\text { utara }\end{array}$ & $\begin{array}{l}\text { S102: meningkatkan kapasitas } \\
\text { membangun kerjasama serta } \\
\text { kegiatan terpadu dan } \\
\text { berkelanjutan dalam } \\
\text { mengelola mengamankan } \\
\text { wilayah KPHP unit II }\end{array}$ & $\begin{array}{l}\text { W102: mengembangkan system pengelolaan dan } \\
\text { pembinaan masyarakat secara terpadu lintas sektoral } \\
\text { W202: membangun dukungan pemerintah daerah } \backslash \\
\text { W302: singkronisasi program pemerintah daerah dan } \\
\text { KPHP unit II }\end{array}$ \\
\hline $\begin{array}{l}\text { 1. Perladangan telah berlangsung } \\
\text { lama dan telah menjadi budaya } \\
\text { petani }\end{array}$ & $\begin{array}{l}\text { S1T1: mengembangkan } \\
\text { sistim kemitraan dalam } \\
\text { pengelolaan kawasan hutan. }\end{array}$ & $\begin{array}{l}\text { W1T1: membangun sistem pengendalian perladangan } \\
\text { secara terpadu } \\
\text { W2T1: menjalin kerjasama dengan LSM untuk } \\
\text { memberdayakan peladang diluar kawasan } \\
\text { W3T1: mengembangkan sistem pencegahan } \\
\text { W4T1: memberlakukan sangsi agar tercapai pengelolaan } \\
\text { yang efektif }\end{array}$ \\
\hline $\begin{array}{l}\text { 2. Adanya klaim lahan dalam } \\
\text { kawasan sebagai tanah milik dan } \\
\text { diperjualbelikan }\end{array}$ & $\begin{array}{l}\text { S1T2: mengembangkan } \\
\text { tataguna lahan ditingkat desa }\end{array}$ & $\begin{array}{l}\text { W1T2: membangun partisipasi stakeholder dalam } \\
\text { pengendalian jual beli lahan hutan } \\
\text { W2T2: membangun kesadaran masyarakat } \\
\text { W3T2: menjalin kerjasama dengan tokoh masyarakat } \\
\text { ditingkat desa/kecamatan }\end{array}$ \\
\hline
\end{tabular}


Berdasarkan matrik SWOT diatas dapat dilihat adanya 18 (delapan belas strategi) dipilih 10 (sepuluh) strategi yang dianggap prioritas dalam pencapaian tujuan pengelolaan kawasan hutan yaitu :

S1 : Menjaga komitmen dan menggalang partisipasi masyarakat

S2 : Meningkatkan kapasitas pengelolaan wilayah KPHP unit II kabupaten Bolaang Mongondow membangun kerjasama serta program terpadu dan berkelanjutan dengan instansi terkait.

S3 : Mengembangkan kemitraan yang terpadu

S4 : Mengembangkan tata guna lahan ditingkat desa.

S5 : Memberdayakan peran LSM, dan tokoh masyarakat sekitar kawasan wilayah KPHP unit II kabupaten Bolaang Mongondow dalam kegiatan pengelolaan kawasan hutan.

S6 : Menetapkan lokasi sasaran prioritas kegiatan pengelolaan yang berdampak langsung bagi perlindungan sistem hidrologis

S7 : Mengembangkan jenis - jenis yang memiliki nilai ekonomi dan ekologi

S8 : Mengembangkan sisitim rehabilitasi dan pembinaan kepada masyarakat secara terpadu lintas sektoral

S9 : Membangun dukungan pemerintah daerah kabupaten dan propinsi dalam implementasi pengelolaan kawasan hutan diwilayah KPHP unit II kabupaten Bolaang Mongondow

S10 : Membangun partisipasi stakeholder dalam pengendalian jualbeli lahan kawasan hutan wilayah KPHP unit II kabupaten Bolaang Mongondow.

Selanjutnya analisis mengenai keluaran dan dampak yang ditimbulkan dalam kegiatan pengelolaan wilayah KPHP unit II kabupaten Bolaang Mongondow.

(1) Menjaga komitmen wilayah KPHP unit II kabupaten Bolaang Mongondow dan menggalang partisipasi masyarakat.

Dari analisis SWOT diperoleh hasil dalam kuadran II yaitu difersifikasi strategi. Artinya organisasi disarankan untuk mengubah strategi sebelumnya sebab, strategi yang lama dikhawatirkan sulit untuk dapat menangkap peluang yang ada sekaligus memperbaiki kinerja organisasi.
(2) Meningkatkan kapasitas KPHP membangun kerjasama serta program terpadu yang berkelanjutan dengan instansi terkait

Tantangan yang dihadapi dalam pengelolaan $\mathrm{KPH}$ sangat rumit karena melibatkan masalah sosial ekonomi dan budaya masyarakat sekitar. Selain dibutuhkan komitmen yang kuat dari pihak KPH juga perlu didukung oleh kapasitas tenaga lapangan yang handal memiliki kemampuan bernegosiasi dengan parapihak terutama dengan masyarakat peladang. Pelaksanaan pengelolaan kawasan akan menjadi sia-sia jika masyarakat setempat yang akan dijadikan mitra pengelola tidak mendukung, baik dalam bentuk partisipasi menjaga dan memelihara tanaman juga terlibat dalam keutuhan kawasan. Disamping itu dibutuhkan keterlibatan para pihak formal baik ditingkat kabupaten maupun propinsi (dinas kehutanan, dinas pertanian, peternakan) untuk mengembangkan pembinaan masyarakat, sekitar kawasan secara terpadu oleh karena itu dibutuhkan kemampuan pihak KPH berkoordinasi dan mengajak seluruh stakeholder terlibat dalam pemecahan masalah dan dukungan masyarakat merupakan strategi yang harus dijalankan. Keluaran dari strategi ini diharapkan dapat memperlancar pelaksanaan pengelolaan hutan serta menjamin kelangsungan pertumbuhan tanaman. Dampak yang diharapkan adalah terpulihkannya kondisi hidrologis kawasan yang pada akhirnya akan meningkatkan kapasitas irigasi dari sarana irigasi yang telah dibangun diwilayah KPHP unit II kabupaten Bolaang Mongondow untuk menunjang ketahanan pangan daerah maupun nasional. Upaya yang akan dilakukan KPH adalah : (1) Mendorong dan memfaslitasi koordinasi lintas sektoral parapihak yang terkait dalam perlindungan dan pengelolaan kawasan hutan, (2) Memfasilitasi pertemuan berkala antara komunitas sekitar kawasan hutan terutama antara pengguna air, dan masyarakat hulu untuk membangun kesepahaman pentingnya konservasi didaerah dan masyarakat sekitar. (3) Mengembangkan sistim pengendalian perambahan hutan secara terpadu ( penanganan didalam kawasan dan diluar kawasan). Penyebab meningkatnya perambahan hutan disebabkan oleh factor yang kompleks baik aspek sosal ekonomi, budaya dan kebijakan maupun aspek biofisik. 
Daerah sekitar wilayah KPHP unit II adalah lokasi transmigrasi baik transmigrasi nasional maupun lokal. Pertumbuhan penduduk yang cukup tinggi serta budaya penduduk lokal yang cenderung boros, menyebabkan sebagian besar lahan pertanian milik penduduk lokal dijual kepada pendatang. Oleh sebab itu perlu penanganan terpadu melalui pembinaan daya dukung kawasan penyangga melalui pengembangan sektor peternakan dan sektor lainnya agar ketergantungan terhadap lahan didalam kawasan dapat dikurangi.

Strategi pelaksanaan pengelolaan hutan di wilayah KPHP unit II dirumuskan berdasarkan analisis SWOT yang dijabarkan sebagai berikut :

a) Strategi penetapan lokasi prioritas dan
urgen

Berdasarkan potensi yang dimilikinya, $\mathrm{KPH}$ merupakan asset alam yang memiliki prospek sangat baik bagi meningkatkan penghasilan masyarakat dan pendapatan negara dari waktu kewaktu serta mempunyai kontribusi yang besar bagi pembangunan, baik daerah maupun nasional secara berkesinambungan. Adapun prospek dan kontribusi utama yang dapat diberikan oleh KPHP dalam kaitannya dengan pembangunan daerah antara lain terpeliharanya daerah tangkapan air yang terdapat di didalam kawasan wilayah KPHP unit II kabupaten Bolaang Mongondow akan menjamin ketersediaan produksi air bagi waduk yang ada di desa Pindol sehingga dengan sendirinya suplai air bagi lahan pertanian baik dihilir maupun disekitar wilayah KPHP unit II akan tetap tersedia. Waduk ini sangat membantu bagi pertanian sehingga kecamatan Lolak dan sekitarnya dapat merasakan manfaatnya. Hal ini menunjukkan betapa pentingnya kawasan wilayah KPHP unit II kabupaten Bolaang Mongondow sebagai sumber air untuk mendukung sector pertanian dan ketahanan pangan.

Masalah utama yang dihadapi dalam mengoptimalkan fungsi tata air kawasan hutan KPHP unit II adalah perambahan hutan yang makin meluas, pertambangan liar serta penebangan liar. Kondisi tersebut telah berdampak negative terhadap sarana irigasi yang dibangun akibat laju sedimentasi dan fluktuasi debit sungai yang makin tinggi. Konflik penguasaan lahan dalam kawasan hutan serta rendahnya persepsi masyarakat terhadap kawasan hutan dan ketimbangan manfaat yang diterima masyarakat hulu dan hilir ( pengguna air) serta masalah sosial budaya lainnya yang bersifat kompleks sebagai penyebab bertambahnya tingkat kerusakan kawasan hutan.

b) Pengembangan potensi pariwisata alam untuk peningkatan pemanfaatan jasa lingkungan.

Salah satu tujuan pengelolaan KPHP unit II adalah meningkatkan peran dalam pengembangan pariwisata dan rekreasi. Perkembangan pariwisata sangat terkait dengan perkembangan sektor ekonomi lainnya, baik secara makro maupun mikro. Dalam kerangka pengelolaan kawasan hutan wilayah KPHP unit II maka strategi yang dikembangkan adalah sinkronisasi antara pengembangan industry pariwisata diarahkan untuk meningkatkan kesadaran masyarakat sekitar tentang makna industry jasa pariwisata yang dapat meningkatkan pendapatan masayarakat, perluasan lapangan kerja, dan membuka komunikasi antar masyarakat.

c) Peningkatan persepsi dan partisispasi parapihak formal

Ada anggapan parapihak didaerah baik propinsi maupun kabupaten bahwa tugas perlindungan dan pelestarian kawasan wilayah KPHP unit II kabupaten Bolaang Mongondow adalah tugas KPH itu sendiri, dilain pihak manfaat jasa lingkungan yang dihasilkan secara langsung terkait dengan kepentingan pemerintah daerah dan masyarakat skitar. Beban tugas yang sangat kompleks dari KPHP unit II tentunya memerlukan partisipasi parapihak terutama berkaitan dengan pengendalian perambahan hutan. program pemberdayaan, penyadaran dan pengendalian perambahan perlu dilakukan secara terpadu sehingga upaya pengelolaan bermanfaat dalam mencegah kerusakan hutan yang lebih parah.

d) Pengembangan keterpaduan pembangunan ketahanan pangan dengan kegiatan reboisasi dan konservasi kawasan hutan.

Berdasarakan rencana strategis Kementrian Kehutanan dalam rencana pembangunan jangka menengah nasional (RPJMN) tahun 2015-2019, telah menetapkan arah dan strategi pembangunan yang terkait dengan tugas dan fungsi kementrian kehutanan yang di arahkan pada 2 (dua) prioritas bidang, yaitu :

1) Dukungan SDA dan LH terhadap perekonomian berbasis SDA.

2) Peningkatan kualitas LH. 


\section{KESIMPULAN DAN SARAN}

\section{Kesimpulan}

1. Kondisi sosial ekonomi masyarakat di enam (6) wilayah kecamatan tersebut memberi gambaran kondisi sosial ekonomi sekitar kawasan hutan yang akan menerima dampak dan manfaat pengelolaan KPHP unit II. Sektor pertanian masih merupakan sumber mata pencaharian utama masyarakat. Sektor pertanian terdiri dari sub sector tanaman pangan, perkebunan, perikanan dan peternakan. Komoditas yang menonjol dari hasil-hasil tanaman pangan terdiri atas padi/beras dan jagung. Hasil perkebunan masih mengandalkan kelapa/kopra dan mulai mengembangkan komoditas coklat serta hasil-hasil perikanan laut terutama perikanan tangkap. Sektor pertanian sebagai mata pencaharian utama masyarakat, namun produksi hasil-hasil pertanian masih memiliki tingkat produktifitas yang rendah, sehingga perlu ditingkatkan kuantitas, jenis komoditas dan kualitasnya untuk meningkatkan pendapatan dan daya beli masyarakat yang masih tergolong rendah.

2. Diwilayah KPHP unit II kabupaten Bolaang Mongondow heterogen yang terdiri dari berbagai macam etnis Mongondow, Minahasa, Sanger, Gorontalo, jawa, Bugis dan lainnya. Terdapat kecenderungan diberbagai tempat para pemilik tanah terutama petani sangat mudah mempertaruhkan dan menjual lahan pertaniannya untuk berbagai keperluan yang seringkali tidak terlalu vital, seperti untuk acara pesta perkawinan dan kebutuhan menyambut acara keagamaan, dan sebagainya. Selain itu tradisi membagi-bagi tanah warisan orang tua kepada anak-anak secara turun-temurun, sehingga rata-rata pemilikan lahan cenderung menyempit. Tingginya bahaya erosi yang terjadi disebabkan kondisi geografi lahan yang berbentuk pegunungan dengan kemiringan lereng yang berkisar antara sedang sampai curam serta tindakan usaha tani dan pengelolaan lahan yang buruk Sejauh ini pengelolaan lahan sudah dilakukan oleh petani dengan sistem agroforestry namun masih sebatas pada tanaman musiman untuk itu perlu ditawarkan tanaman yang mendukung konservasi lahan. Pada lahan datar dan yang berlereng curam pemanfaatan lahan masih dengan cara tradisional pengolahan tanah hanya dengan membuka dan membakarnya masyarakat belum mengusahakan cara mengolah lahan dengan membuat guludan dan terasering pada lahan dan yang berlereng curam.

3. Strategi pelaksanaan pengelolaan hutan diwilayah KPHP unit II kabupaten Bolaang Mongondow adalah terpeliharanya daerah tangkapan air dan menjamin ketersediaan produksi air bagi waduk yang ada di desa Pindol, meningkatkatkan peran dalam pengembangan pariwisata dan rekreasi adanya partisispasi para pihak terutama berkaitan dengan pengendalian perambahan hutan dan menetapkan arah dan strategi pembangunan yang terkait dengan fungsi kementrian kehutanan.

\section{Saran}

Penerapan model pertanian konservasi perlu diterapkan di lahan kering maupun lahan kritis. Kedua lahan ini bisa dikonservasi, tetapi keberhasilannya sangat ditentukan oleh kondisi biofisik, sosial ekonomi, dan keinginan petani. Hal tersebut perlu dicermati mengingat tidak ada satupun teknik konservasi yang sempurna. Setiap teknik konservasi membutuhkan persyaratan tertentu agar teknik tersebut efektif.

\section{DAFTAR PUSTAKA}

Adimihardja, Kusnaka. 1983. Kerangka Studi Antropologi Sosial Dalam Pembangunan. Bandung: Tarsito.

Atsan, T H., B. Isik, F. Yavuz and Z. Yurrtas. 2009. Factors affecting agriculture extention services in Northeast Anatolia Region. African Journal of Agricultural Research Vol. 4 (4), pp.305-310, April, 2009.

BPDAS Tondano. 2014. Review Rencana RTK RHL DAS Di Sulawesi Utara. Laporan Hasil Penelitian. 
Creswell, S. and W. John. 2002, Research Design Qualitative and Quantitative Approaces, Alih Bahasa : Angkatan III dan IV KIK-UI dan bekerjasama dengan Nur Khabibah, Jakarta : KIK Press.

Dixon, J., A. Glulliver, and D. Gibbon. 2001. Farming System and Poverty: Improving Farmers Livelihood in a changing Word. FAO dan Word Bank. Rome and Washington D.C. Published Multimedia service,Information Division,FAO, Vialle Delle Terme di Caracalla, 00100 Rome, Italy. ISBN 925-104627-1 p 409.

Galudra, G., G. Pasya, M Sirait, and C. Fay 2006. Rapid tenur Assesment. Word Agroforestry Centre Asia.Volume I. p11. 24/2- 2010 .

Garna, J.K. 1995. Kearifan Masyarakat Dalam budidaya Dan Penggunaan Lahan: Makalah Dalam Seminar Budaya Dan Budidaya Pertanian: Pelestarian, Perubahan, Dan Pertukaran (Culture dan Agriculture: Preservation, Change and Exchange), Bukittinggi, Departemen Pertanian dan Departemen Pendidikan Dan Kebudayaan- Direktorat Jenderal Kebudayaan, RI.

Juo, A.S.R. and Manu, A. 1996. Agriculture, Ecosystems, and Environment : Chemical Dinamic in Slash and Burn Agriculture. 58: 49-60.

Langi, M. dan H. Walangitan. 2013. Kajian akademik pembentukan kelembagaan KPHP Wilayah II Kabupaten Bolaang Mongondow Sulawesi Utara.

Lubis, Z. 1997. Repong Damar: Kajian Tentang Pengambilan Keputusan Dalam pengelolaan Lahan Hutan Di Pesisir krui, Lampung Barat.
Moleong, L.J., 2012. Metode Penelitian Kualitatif. Edisi Revisi. Bandung: Rosdakarya.

Moore, W.E. 1967. Order and Change; Essays in Comparative Sociology, New York, John Wiley \& Sons.

Mudiyono. 1990. Perubahan Sosial dan Ekologi Peladang Berpindah, Pontianak:Dalam Suara Almamater Universitas Tanjungpura, No II Tahun V Nopember 1990.

Reijntjes. H. 1999. Pertanian Masa depan. Pengantar Untuk Pertanian Berkelanjutan Dengan Input Luar Rendah.

Setyawan, S. 1997. Analisis Keputusan Petani Dalam Menerapkan Usaha Konservasi Pada Lahan Berlereng. Studi Kasus Desa Cintaasih, Kabupaten Cianjut Jawa Barat. Lembaga Penelitian dan Pengabdian Kepada Masyarakat. IPB Bogor.

Silalahi, U. 2010. Metode Penelitian Sosial. Refika Aditama. ASBN 979-1073-9.

Siregar, H. 2006. Social - Economic Reasons To Soil conversation : An Econometric Analisis on Cross-Setion Lore Lindu Data. Jurnal Agro Ekonomi, Volume 24 nomor 1 pp. 1-20.

Walangitan, H., O. Rotinsulu, dan T. Franz. 2014. Bisnis Plan KPHP Model Poigar. Dinas Kehutanan Propinsi Sulawesi Utara. 